\title{
Microphysical sensitivity of coupled springtime Arctic stratocumulus to modelled primary ice over the ice pack, marginal ice, and ocean
}

Gillian Young et al.

Correspondence to: Gillian Young (gillian.young@manchester.ac.uk) and Thomas W. Choularton (choularton@ manchester.ac.uk)

The copyright of individual parts of the supplement might differ from the CC-BY 3.0 licence. 


\section{Supplementary Material}

\section{Dropsonde dry bias}

A possible dry bias was influencing the dropsonde data used to initialise the LEM, producing a drier boundary layer than was observed. Of the data used to initialise the model, only the qvap field (as shown in Fig. 3) was affected. Cloud fields

5 are initialised with an adiabatic liquid water mixing ratio profile; therefore, this bias only has a small effect on the modelled cloud structure. However, the rate at which precipitation develops is affected and highlights an additional sensitivity of cloud structure to the humidity of the boundary layer in each case.

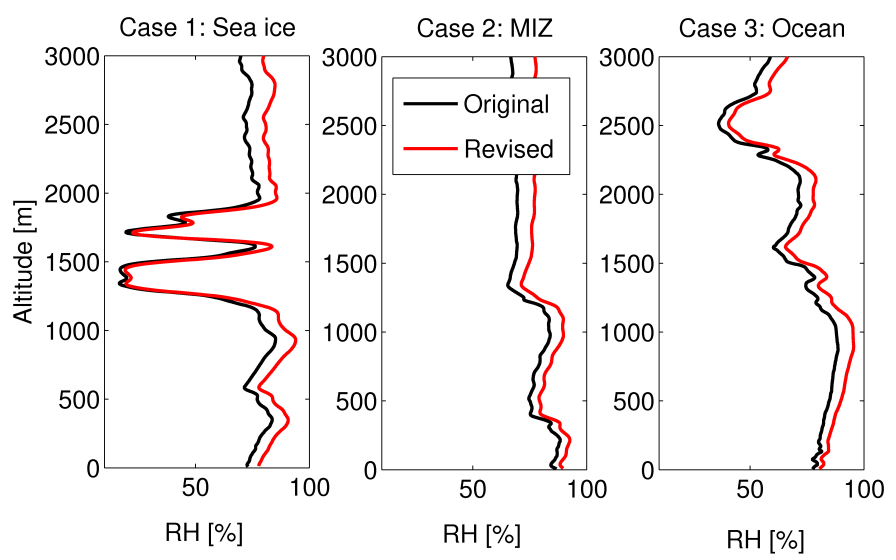

Figure S1. Relative humidity (RH) dropsonde measurements. Original data (black) was used to initialise the LEM in the presented simulations. Revised data is shown in red.

Figures illustrating the extent of this dry bias are included as follows. Relative humidity data are shown in Fig. S1. An equivalent version of Fig. 3 is included to demonstrate the revised $q_{v a p}$ profiles (Fig. S2). Additionally, an example test simulation with revised dropsonde profiles from each case is included for justification.
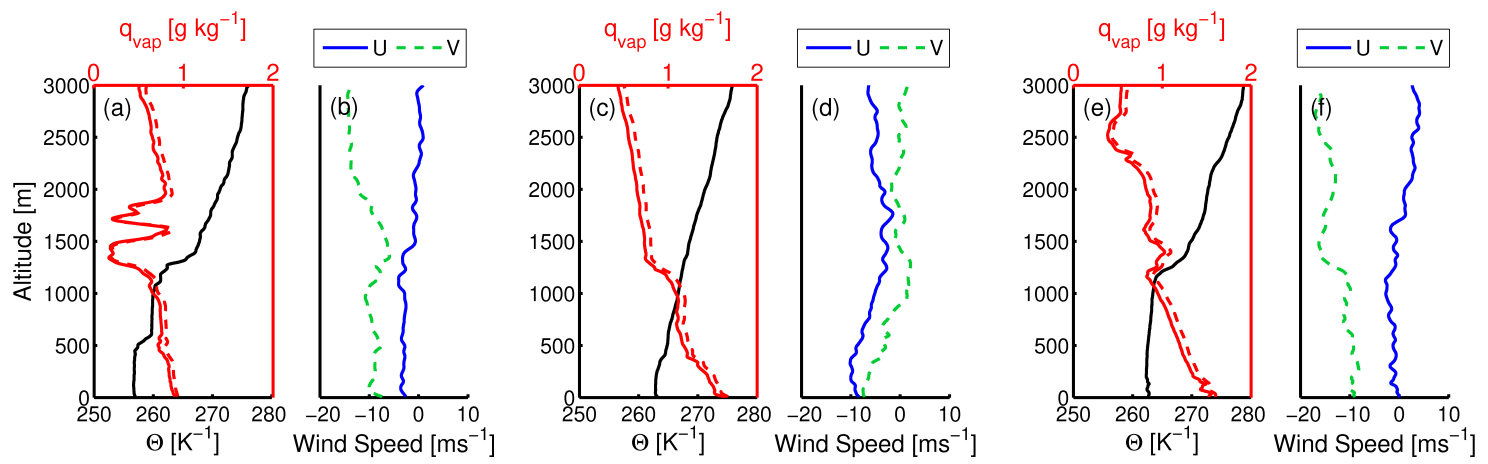

Figure S2. As Fig. 3 with revised quap data shown by a dashed (red) line in panels a, c, and e. 
Figure S3 shows the equivalent simulation to Fig. 5(a) with the revised humidity profiles. Our conclusions remain unchanged with this new data: using C86 under the deposition-condensation conditions commonly used in WRF causes the production of an ice cloud with complete suppression of the liquid phase. The mixed-phase conditions observed are inadequately reproduced using these criteria.

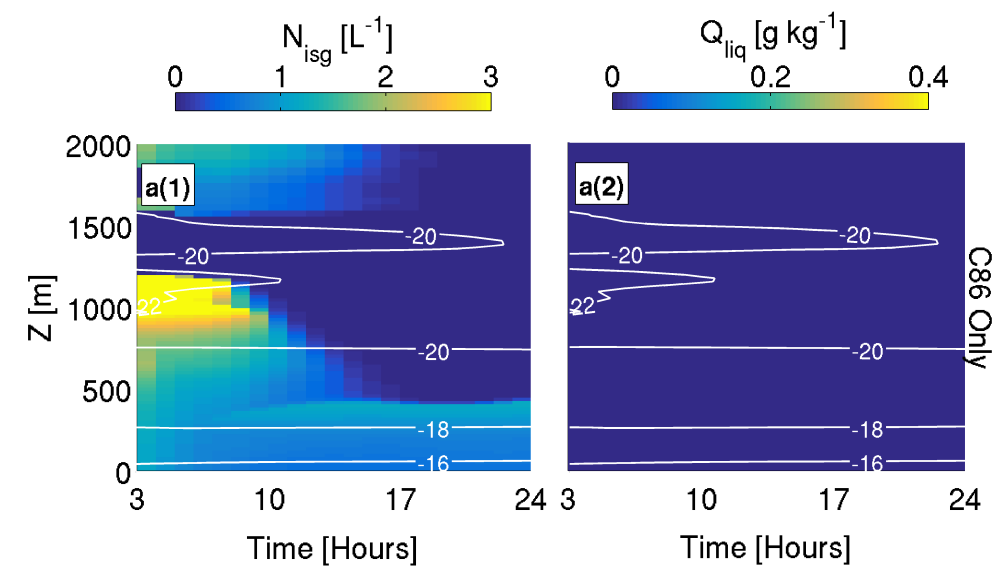

Figure S3. As Fig. 5(a) with revised dropsonde initialisation conditions.

Figure S4 illustrates that increasing the humidity of the boundary layer quickens the formation of the mixed-phase cloud layer in case 2. Cloud top increases to higher altitudes than in the drier case (Fig. 9(c)), and reaches colder temperatures, due to the development of precipitation. The increased humidity allows for more efficient precipitation development, which acts to deplete the liquid phase of the cloud.
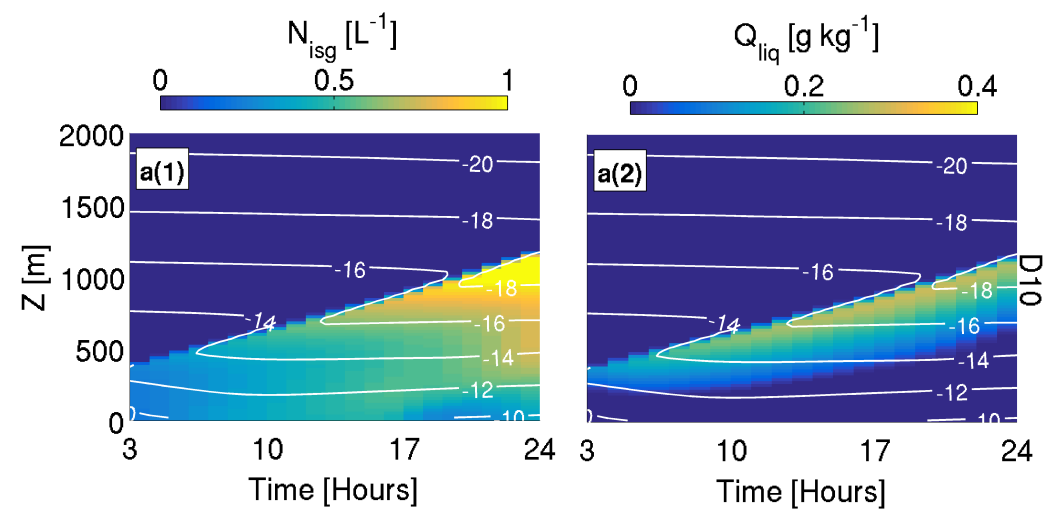

Figure S4. As Fig. 9(c) with revised dropsonde initialisation conditions.

Figure S5 shows the D10 ocean simulation (as Fig. 10(c)) with the revised initialisation profiles. In contrast to the drier conditions, this cloud glaciates by $22 \mathrm{~h}$ and all ice falls out of the cloud by $24 \mathrm{~h}$. No convective features form as the precip- 
itation which forms does so more efficiently with increased humidity, leading to complete cloud break up. Greater number concentrations of large solid hydrometeors (snow and graupel) are simulated at earlier times, leading to cloud break up with no convection development.
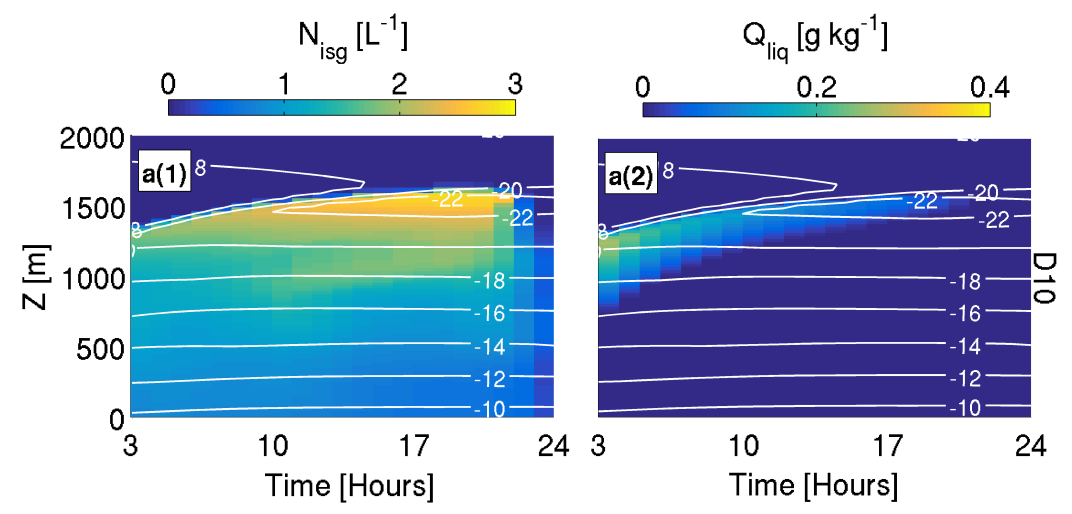

Figure S5. As Fig. 10(c) with revised dropsonde initialisation conditions.
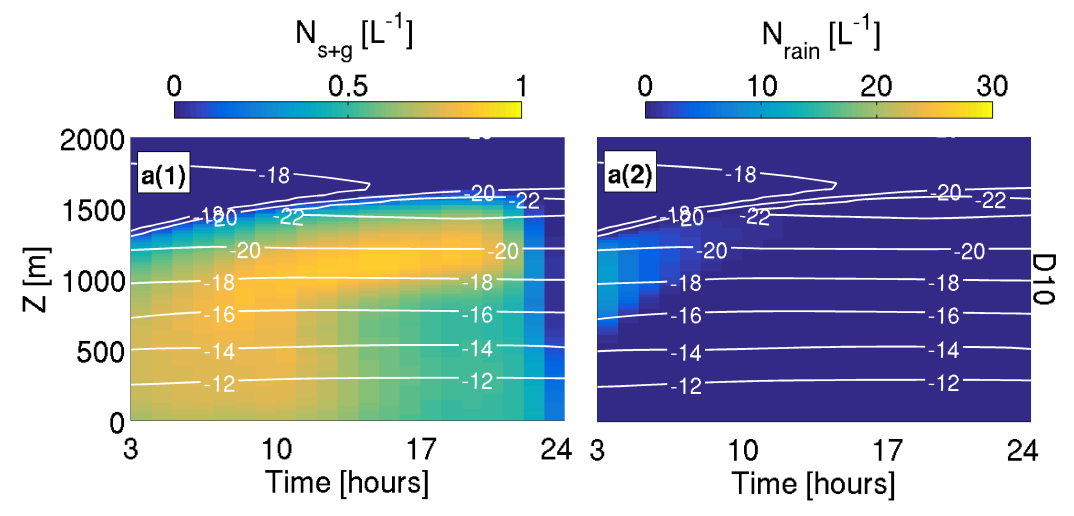

Figure S6. As Fig. 12(a) with revised dropsonde initialisation conditions. 


\section{Bigg immersion-freezing and Meyers contact-freezing}

The influence of immersion- and contact-freezing within the Morrison et al. (2005) microphysics scheme was tested to quantify their contribution to $\mathrm{N}_{\mathrm{isg}}$. Simulations with contact-freezing (Meyers et al. 1992 - hereafter, M92) and immersion-freezing (Bigg 1953 - hereafter, B53) switched either on or off are shown in Fig. S7. The addition of B53 and M92 produces a signif5 icantly larger ice crystal number concentration (up to $3 \mathrm{~L}^{-1}, 1.5 \mathrm{~L}^{-1}$, and $10 \mathrm{~L}^{-1}$ in cases 1,2 , and 3 respectively) than the mean observed $\left(0.47 \pm 0.86 \mathrm{~L}^{-1}, 0.35 \pm 0.20 \mathrm{~L}^{-1}\right.$, and $0.55 \pm 0.95 \mathrm{~L}^{-1}$ respectively, Table 2$)$

Modelled ice number concentrations with and without B53 and M92 active are similar in case 1. Both representations cause glaciation, and liquid water is not modelled at any point during the simulations. No improvement can be seen in the liquid water mixing ratio when both the B53 and M92 nucleation mechanisms are disabled. Modelled ice number concentrations for case 2 peak at $\sim 1.5 \mathrm{~L}^{-1}$ and $\sim 0.8 \mathrm{~L}^{-1}$ with and without both $\mathrm{B} 53$ immersion- and M92 contact-freezing nucleation active. Both scenarios allow for liquid water to form in the cloud, with $\sim 0.2 \mathrm{~g} \mathrm{~kg}^{-1}$ modelled. When B53 and M92 are active in case 3 , high ice number concentrations are rapidly simulated at approximately $12 \mathrm{~h}-14 \mathrm{~h}$. This event causes the evaporation of all simulated liquid water, and the region of high ice number concentration dissipates back to the original sustained concentration of $\sim 2 \mathrm{~L}^{-1}$ afterwards. This event is not simulated when B53 and M92 are disabled, suggesting these additional sources of ice number are the cause of this phenomenon. 

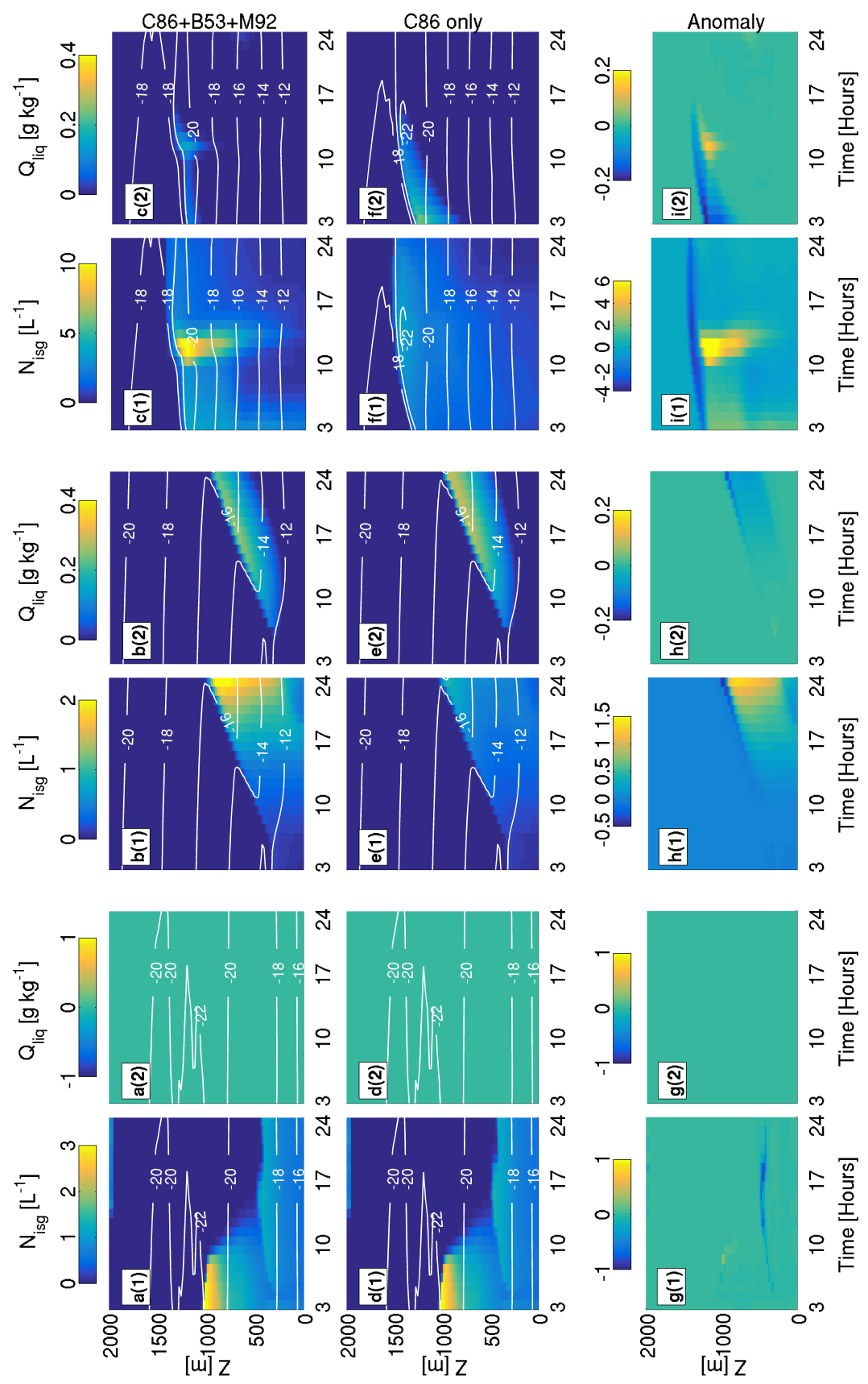

Figure S7. Simulated ice number concentrations $\left(\mathrm{N}_{\mathrm{isg}}, \mathbf{1}\right)$ and liquid water mixing ratios $\left(\mathrm{Q}_{\text {liq }}, 2\right)$ using the Cooper (1986) parameterisation under default WRF conditions $\left(\mathrm{T}<-8^{\circ} \mathrm{C}, \mathrm{S}_{\mathrm{w}}>0.999\right.$ or $\left.\mathrm{S}_{\mathrm{i}}>1.08\right)$. (a, b, c): B53, M92, and C86 active. (d, e, f): C86 depositioncondensation nucleation only. (g, h, i): Anomaly between simulations including B53 and M92 and those using C86 only. (a, d, g): Sea ice (case 1), (b, e, h): MIZ (case 2), (c, f, i): Ocean (case 3). Run length 24 hours. Temperature $\left({ }^{\circ} \mathrm{C}\right.$ ) contours are overlaid in white. Note changing colour bars for each subfigure. 


\section{Supplementary figures}
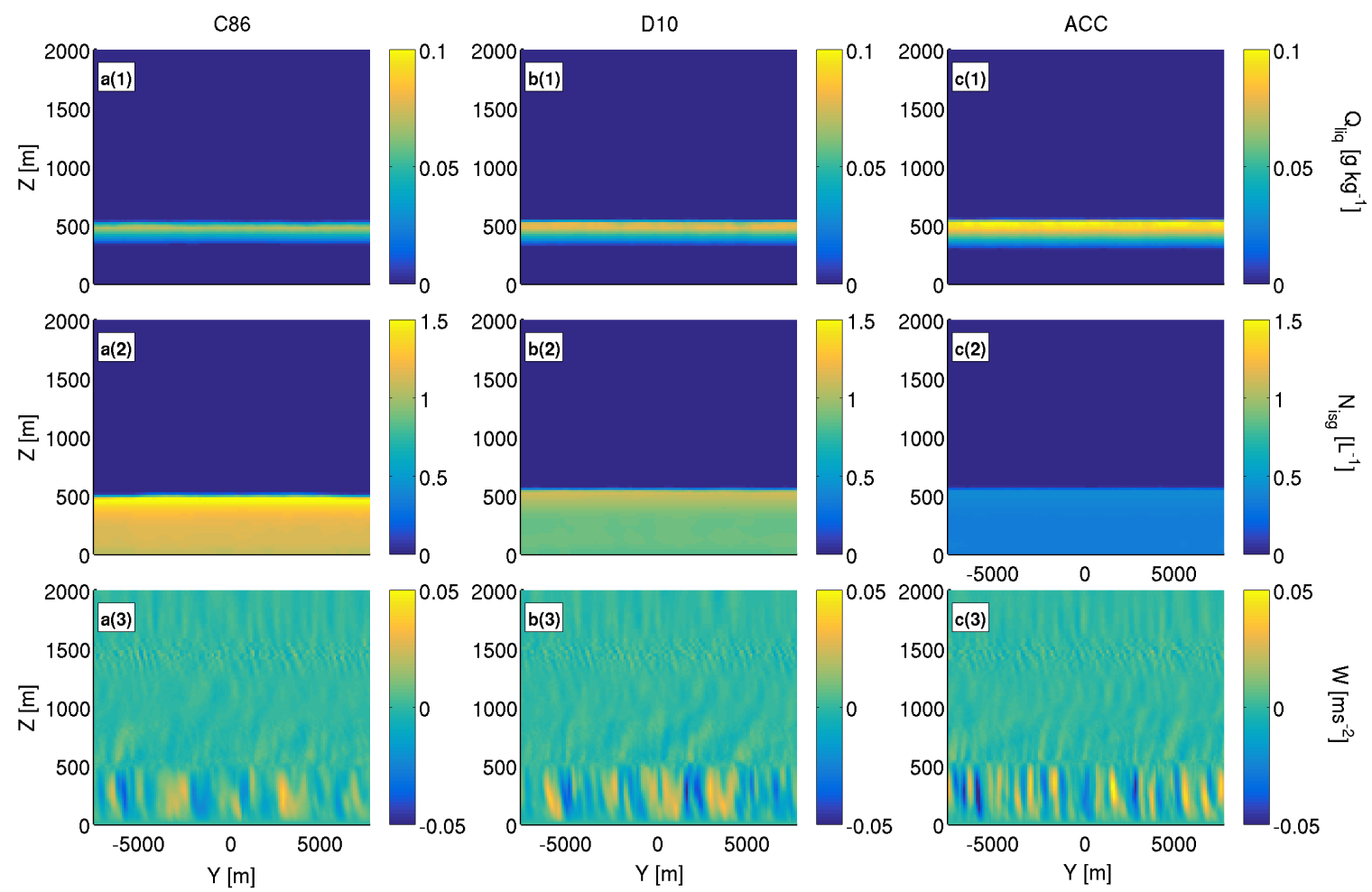

Figure S8. Z-Y slice of modelled $\mathrm{Q}_{\text {liq }}$ (top row), $\mathrm{N}_{\mathrm{isg}}$ (middle row), and vertical velocity (bottom row) at $21 \mathrm{~h}$ over the sea ice (case 1 ). The $\mathrm{N}_{\mathrm{isg}}$ and $\mathrm{Q}_{\text {liq }}$ fields are homogeneous, with liquid layer at cloud top and ice formation throughout. Enhanced turbulent activity, due to the comparatively larger liquid water content, is modelled with ACC (panel c). Note changing colour bars for each subfigure. 

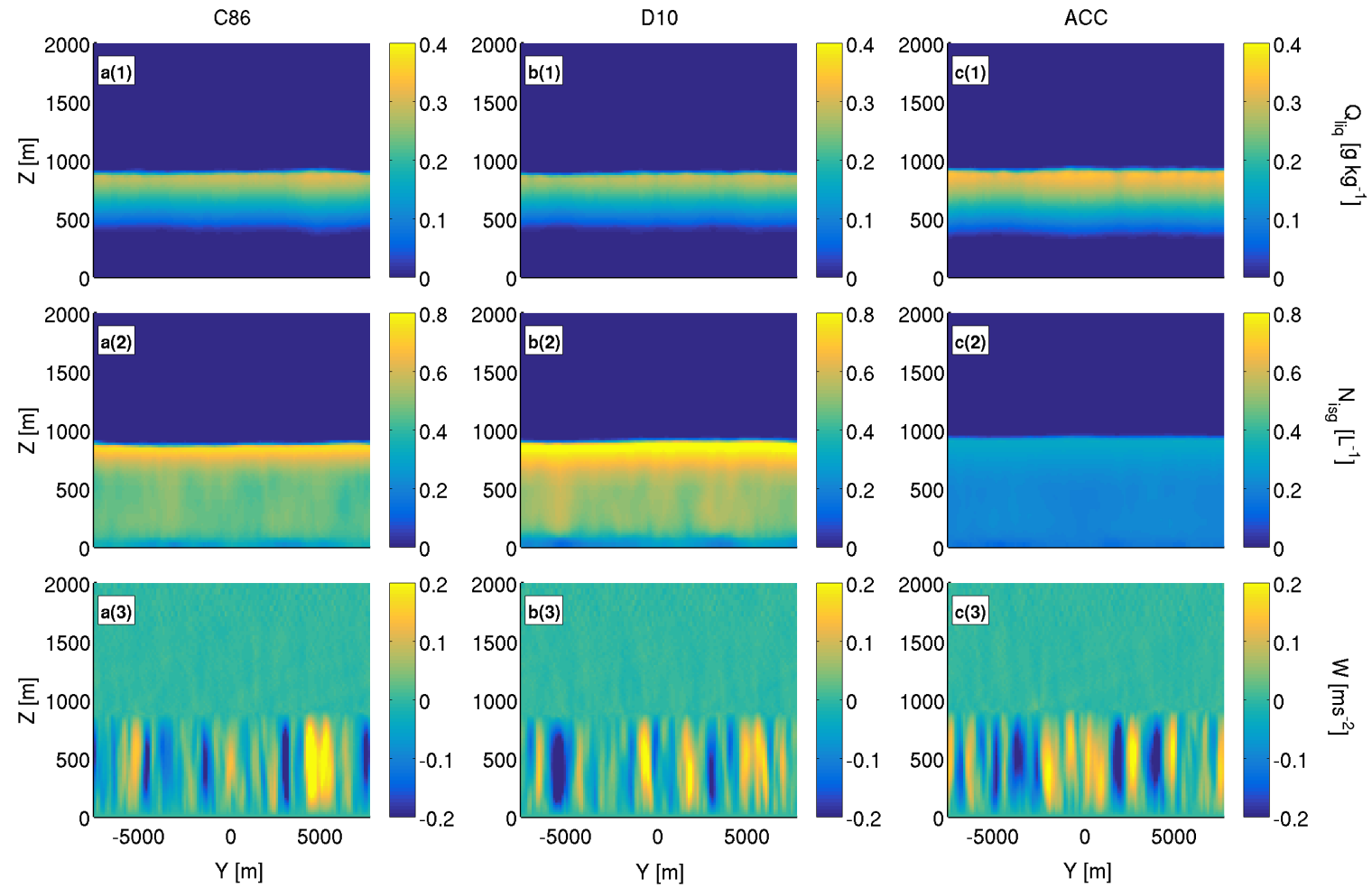

Figure S9. Z-Y slice of modelled $\mathrm{Q}_{\text {liq }}$ (top row), $\mathrm{N}_{\text {isg }}$ (middle row), and vertical velocity (bottom row) at $21 \mathrm{~h}$ over the MIZ (case 2 ). Significant turbulence is simulated within the cloudy layer (bottom row). With comparison to the sea ice case, the liquid layer at cloud top is more heterogeneous in all cases. This is particularly clear in the D10 simulations (panel b), where $\mathrm{N}_{\mathrm{isg}}$ is enhanced in downdraughts. Note changing colour bars for each subfigure. 

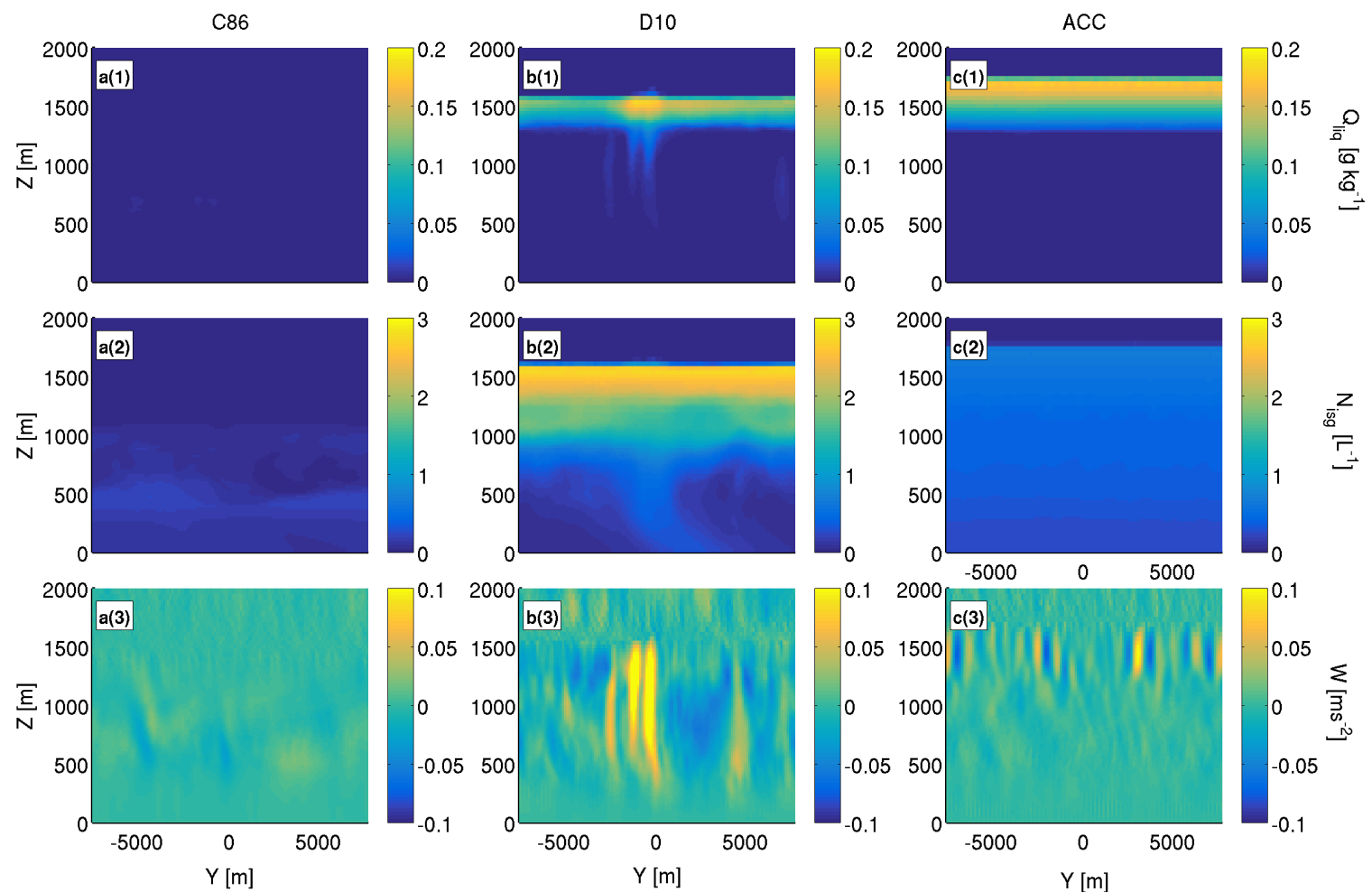

Figure S10. Z-Y slice of modelled $\mathrm{Q}_{\text {liq }}$ (top row), $\mathrm{N}_{\text {isg }}$ (middle row), and vertical velocity (bottom row) at 21 h over the ocean (case 3). Large updraught columns are simulated using D10, which correspond spatially with columns of high $\mathrm{Q}_{\text {liq }}$. These updraughts are co-located with a precipitating (snow) region, evident from the $\mathrm{N}_{\text {isg }}$ figures (second row). C86 (panel a) had dissipated by $21 \mathrm{~h}$; therefore, little activity can be seen in this simulation. Similar to cases 1 and 2, ACC produces a homogeneous liquid layer at cloud top, with ice below (panel c). Note changing colour bars for each subfigure. 


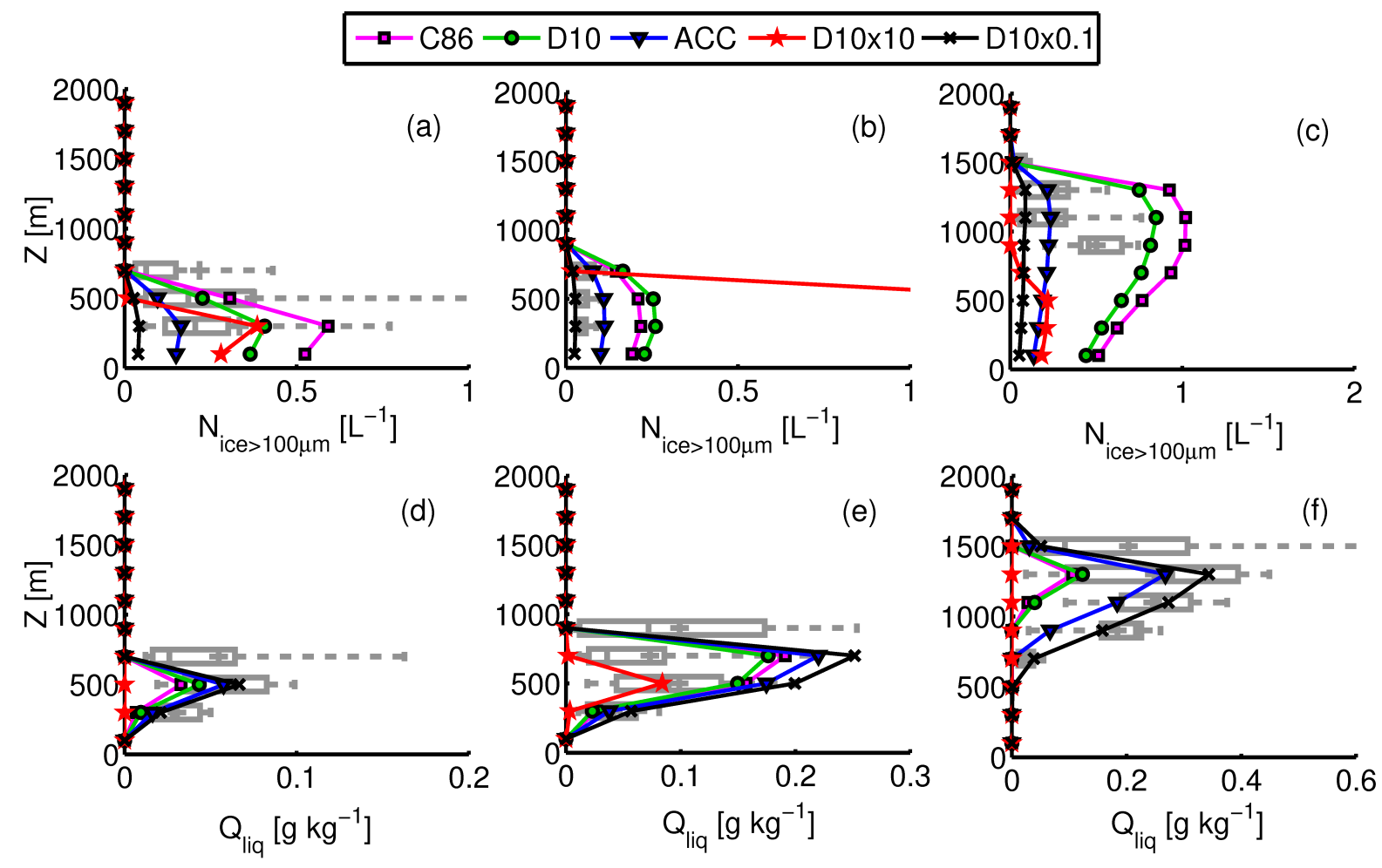

Figure S11. Observed $\mathrm{N}_{\mathrm{ice}>100 \mu \mathrm{m}}$ (top row), and $\mathrm{Q}_{\text {liq }}$ (bottom row) for the sea ice (column 1), MIZ (column 2) and ocean (column 3) cases. Observations are shown as grey boxes. These boxes illustrate data similarly to those in Fig. 7. Modelled $\mathrm{N}_{\mathrm{ice}}>100 \mu \mathrm{m}$, and $\mathrm{Q}_{\mathrm{liq}}$ are overlaid from the C86 (magenta), D10 (green), ACC (blue), D10 $\times 10$ (red), and D10 $\times 0.1$ (black) simulations. Model time steps of $21 \mathrm{~h}, 17 \mathrm{~h}$, and $7 \mathrm{~h}$ are again used for comparison with the sea ice, MIZ, and ocean observations respectively. 

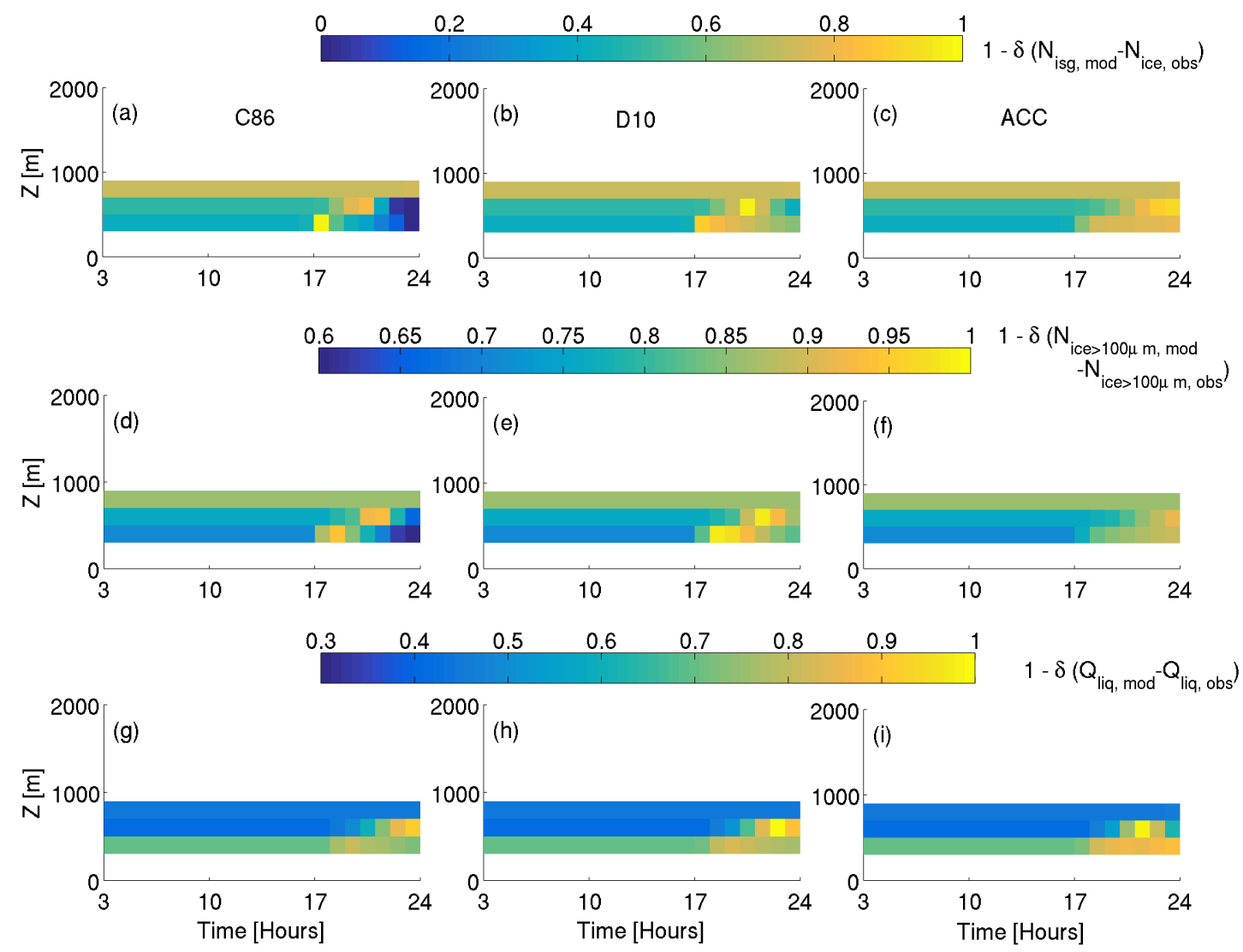

Figure S12. Residual comparison of modelled and observed $\mathrm{N}_{\mathrm{isg}}$ (top row), $\mathrm{N}_{\mathrm{ice}}>100 \mu \mathrm{m}$ (middle row), and $\mathrm{Q}_{\text {liq }}$ (bottom row) in case 1 (sea ice) for each model time step. At each altitude bin, the mean observed quantity is subtracted from the mean modelled. The absolute magnitude of this fraction is then subtracted from 1. Therefore, better agreement between the mean observed and mean modelled values gives a larger fraction (with a maximum of 1). When two of the three parameterisations give good agreement with the $\mathrm{N}_{\mathrm{isg}}$ observations at the same time step, that time step has been selected for comparison with the observations in Fig. 7. For the sea ice simulations, the chosen time step was $21 \mathrm{~h}$. Note changing colour bars for each row. 

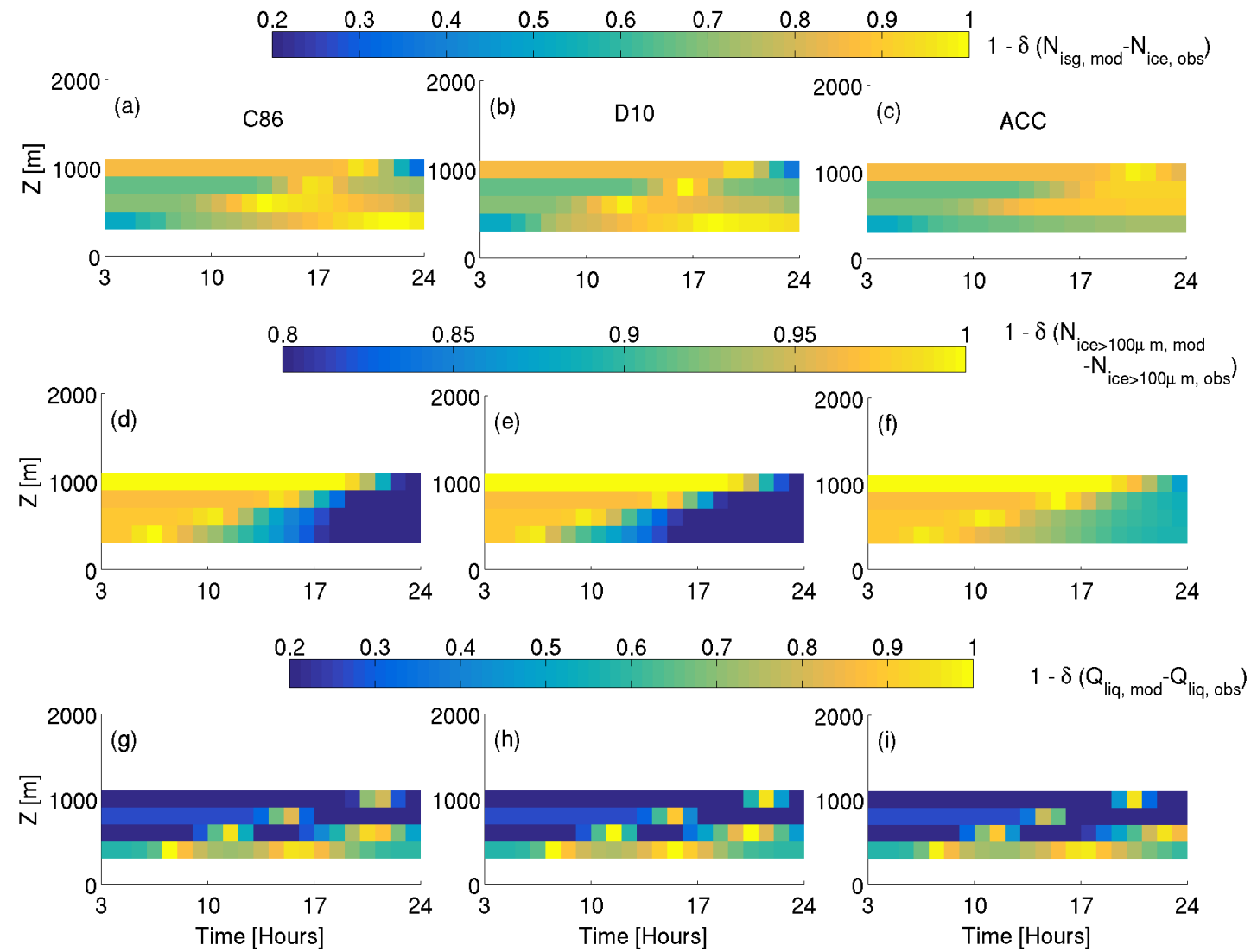

Figure S13. Residual comparison of modelled and observed $\mathrm{N}_{\mathrm{isg}}$ (top row), $\mathrm{N}_{\mathrm{ice}>100 \mu \mathrm{m}}$ (middle row), and Q $\mathrm{Q}_{\text {liq }}$ (bottom row) in case 2 (MIZ) for each model time step. As with Fig. S12, better agreement with the mean observed value gives a larger fraction (with a maximum of 1). For the MIZ simulations, the chosen time step was $17 \mathrm{~h}$. Note changing colour bars for each row. 


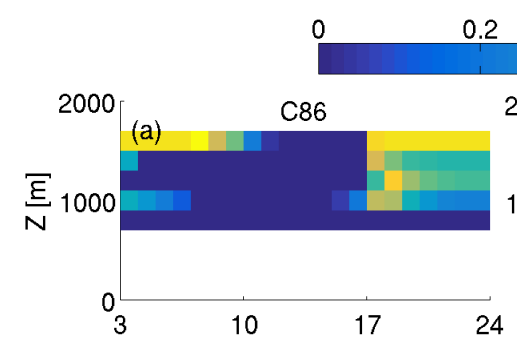

$.2 \quad 0.4$

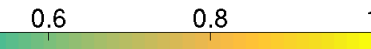

$1-\delta\left(\mathrm{N}_{\text {isg, mod }}{ }^{-\mathrm{N}_{\text {ice, obs }}}\right)$

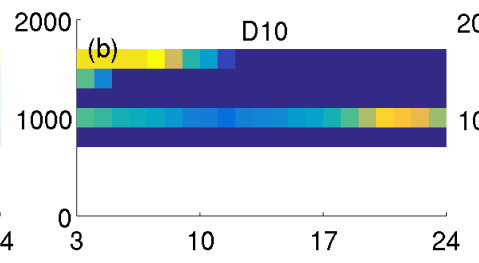

2000

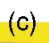
$\mathrm{ACC}$

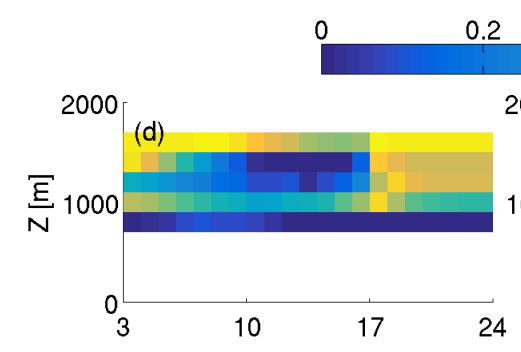

0.2

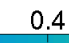

0.6
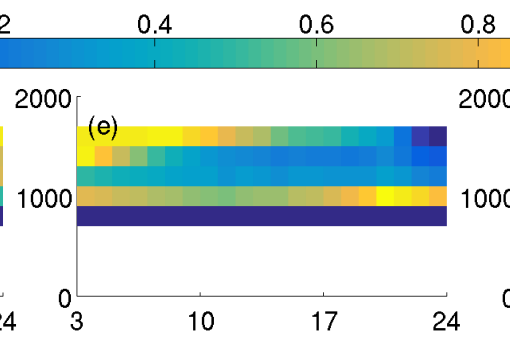

2000
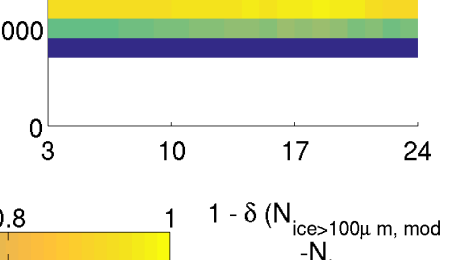
ice $>100 \mu \mathrm{m}$, obs
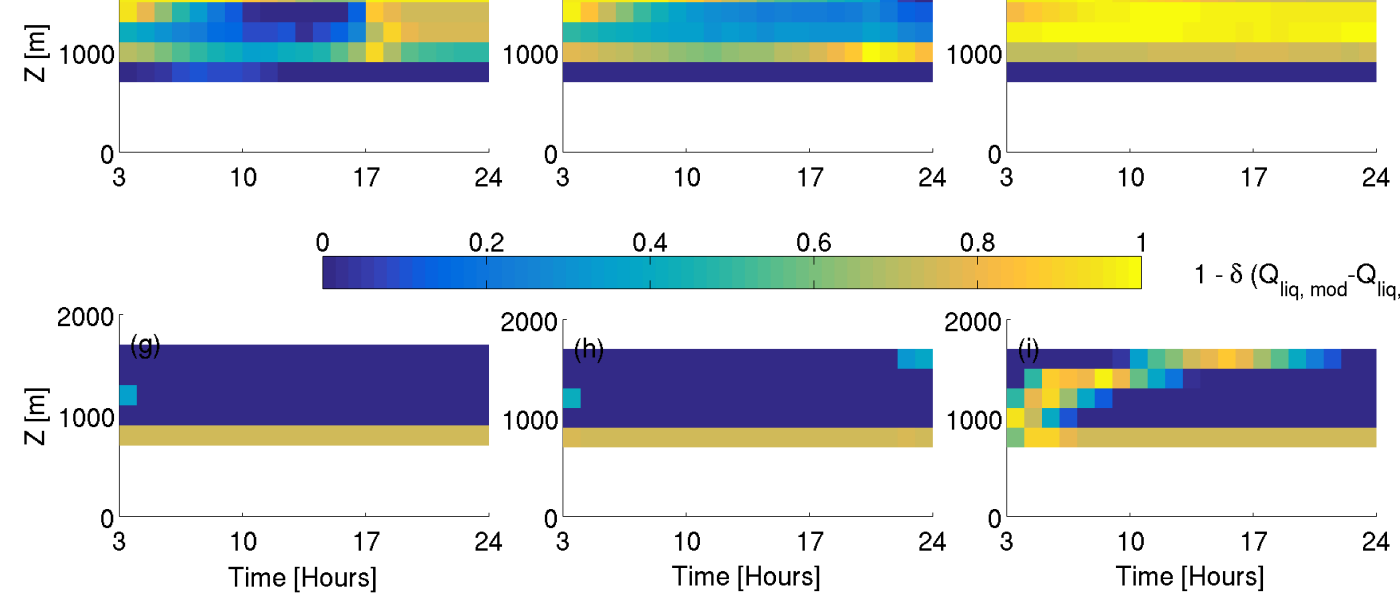

0.2

0.4

0.6

0.8

2000 2000
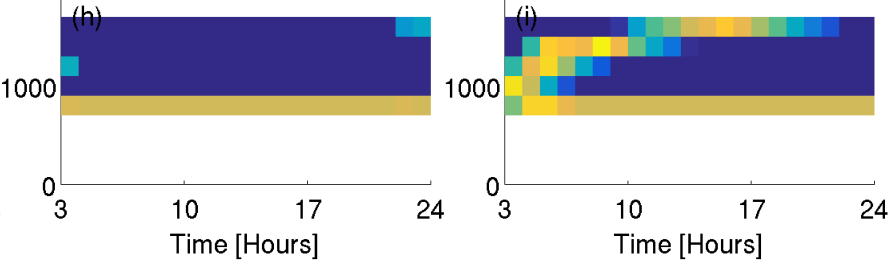

Figure S14. Residual comparison of modelled and observed $\mathrm{N}_{\mathrm{isg}}$ (top row), $\mathrm{N}_{\mathrm{ice}>100 \mu \mathrm{m}}$ (middle row), and Q $\mathrm{Q}_{\text {liq }}$ (bottom row) in case 3 (ocean) for each model time step. As with Fig. S12, better agreement with the mean observed value gives a larger fraction (with a maximum of 1). For the MIZ simulations, the chosen time step was $7 \mathrm{~h}$. Note changing colour bars for each row. 

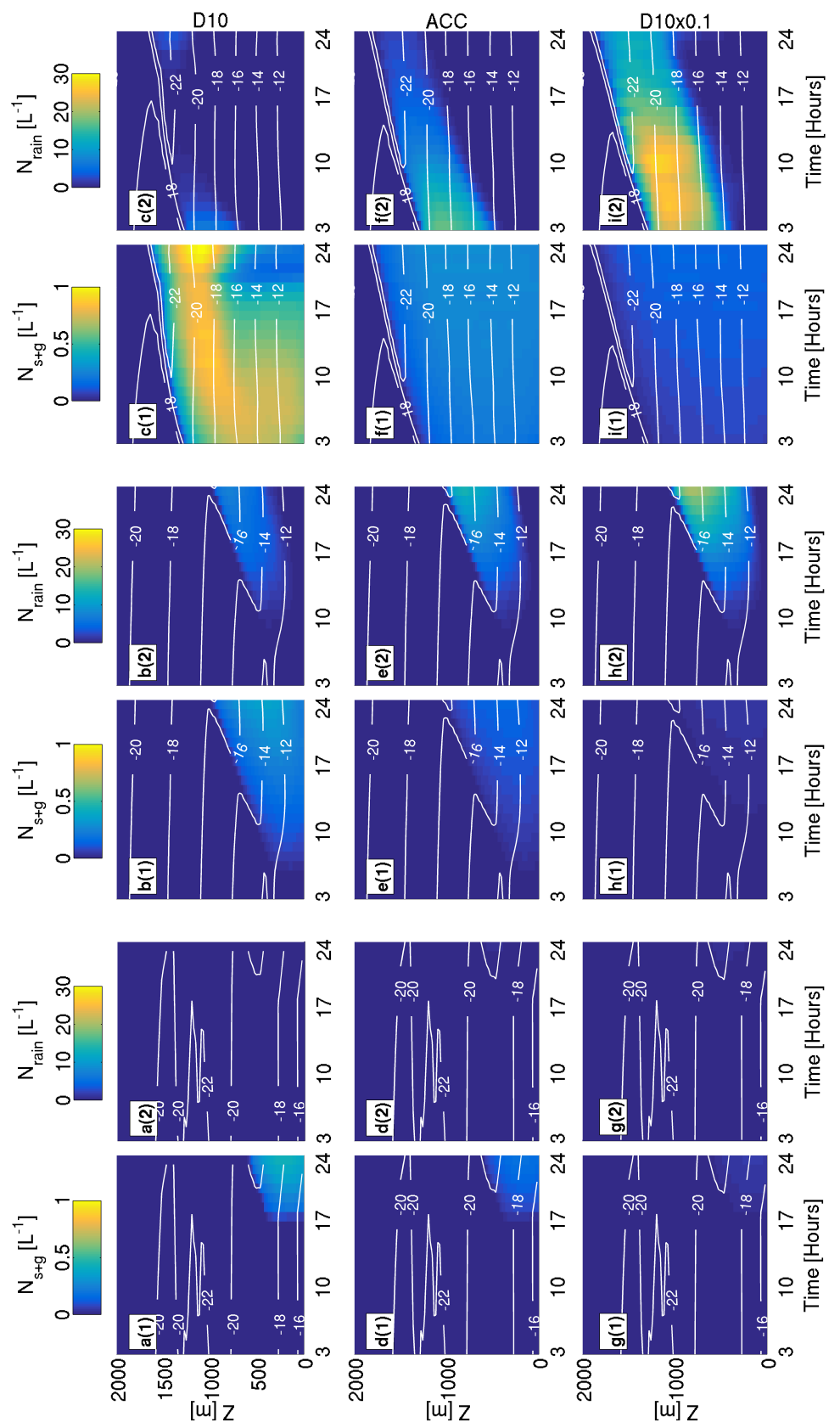

Figure S15. Summed snow and graupel number concentrations $\left(\mathrm{N}_{\mathrm{s}+\mathrm{g}}, 1\right)$ and rain number concentration $\left(\mathrm{N}_{\text {liq }}, 2\right)$ using D10 (top row), ACC (middle row) and D10 $\times 0.1$ (bottom row). (a, d, g): Sea ice (case 1), (b, e, h): MIZ (case 2), (c, f, i): Ocean (case 3 ). Run length 24 hours. Number concentrations of solid precipitable particles increase with simulation time in all cases when using D10, and the rain number concentration behaves similarly in case 2 when applying D $10 \times 0.1$. Overall, small concentrations of large solid and liquid hydrometeors are modelled during the ACC simulations (panels $\mathbf{d}, \mathbf{e}, \mathbf{f}$ ), and almost no precipitable particles are modelled in case 1 with D10 $\times 0.1$ (panel $\mathbf{g}$ ). Note changing colour bar for each column. 

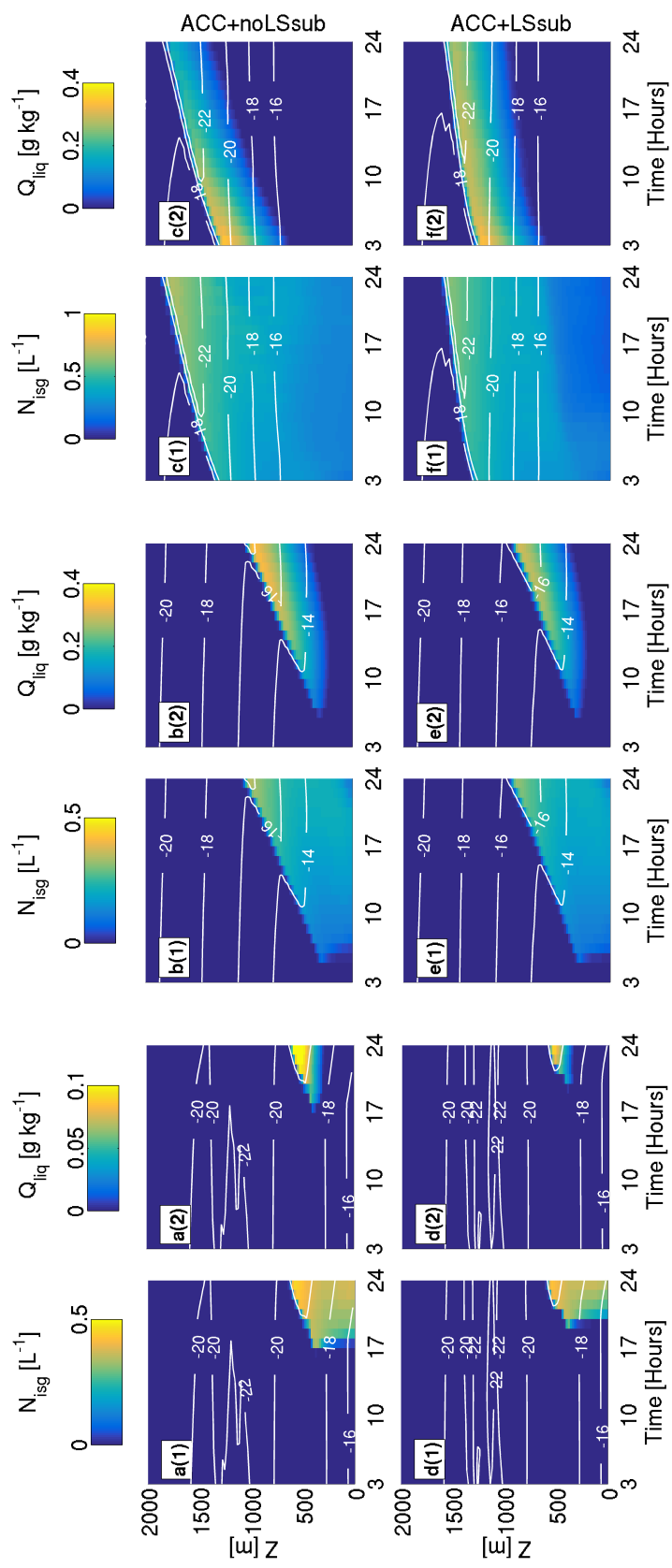

Figure S16. Simulated ice number concentrations $\left(\mathrm{N}_{\mathrm{isg}}, 1\right)$ and liquid water mixing ratios $\left(\mathrm{Q}_{\text {liq }}, 2\right)$ using ACC without large-scale subsidence (top row) and with an imposed subsidence of $2.5 \times 10^{-6} \mathrm{~s}^{-1}$ (bottom row, as in Solomon et al., 2015). All are restricted to water-saturation. (a, d): Sea ice (case 1), (b, e): MIZ (case 2), (c, f): Ocean (case 3). Run length 24 hours. In all cases, cloud top height and $\mathrm{Q}_{\text {liq }}$ is suppressed when large-scale subsidence is imposed. Temperatures are also warmer; however, case 2 is still too cold with comparison to the observations. Note changing colour bars for each subfigure. 

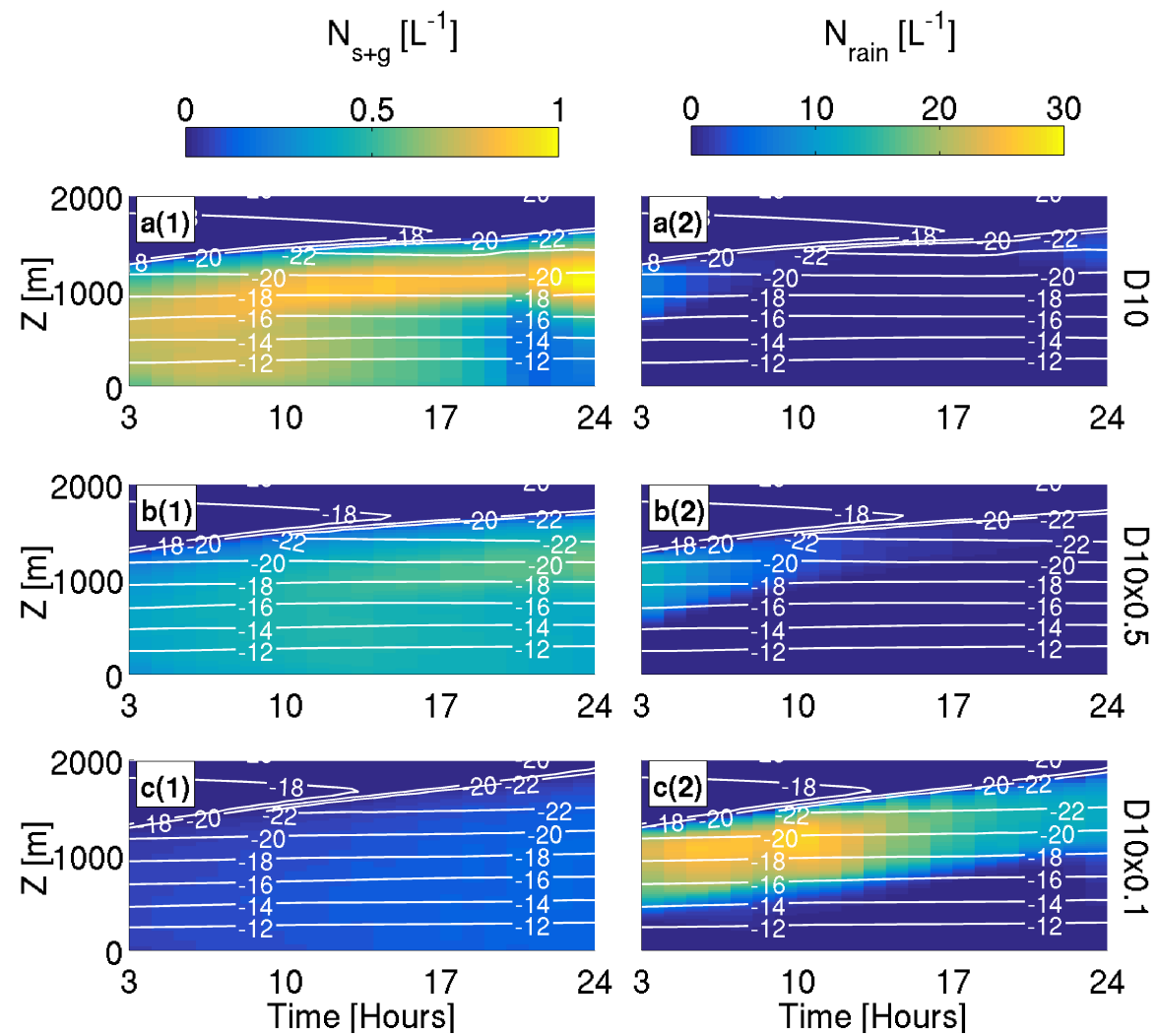

Figure S17. Number concentrations of solid (snow + graupel, $\mathrm{N}_{\mathrm{s}+\mathrm{g}}, \mathbf{1}$ ) and liquid (rain, $\mathrm{N}_{\mathrm{rain}}, 2$ ) precipitable particles modelled during the (a) D10, (b) D10 $\times 0.5$, and (c) D10 $\times 0.1$ simulations over the ocean (case 3). Note changing colour bars for each subfigure. 


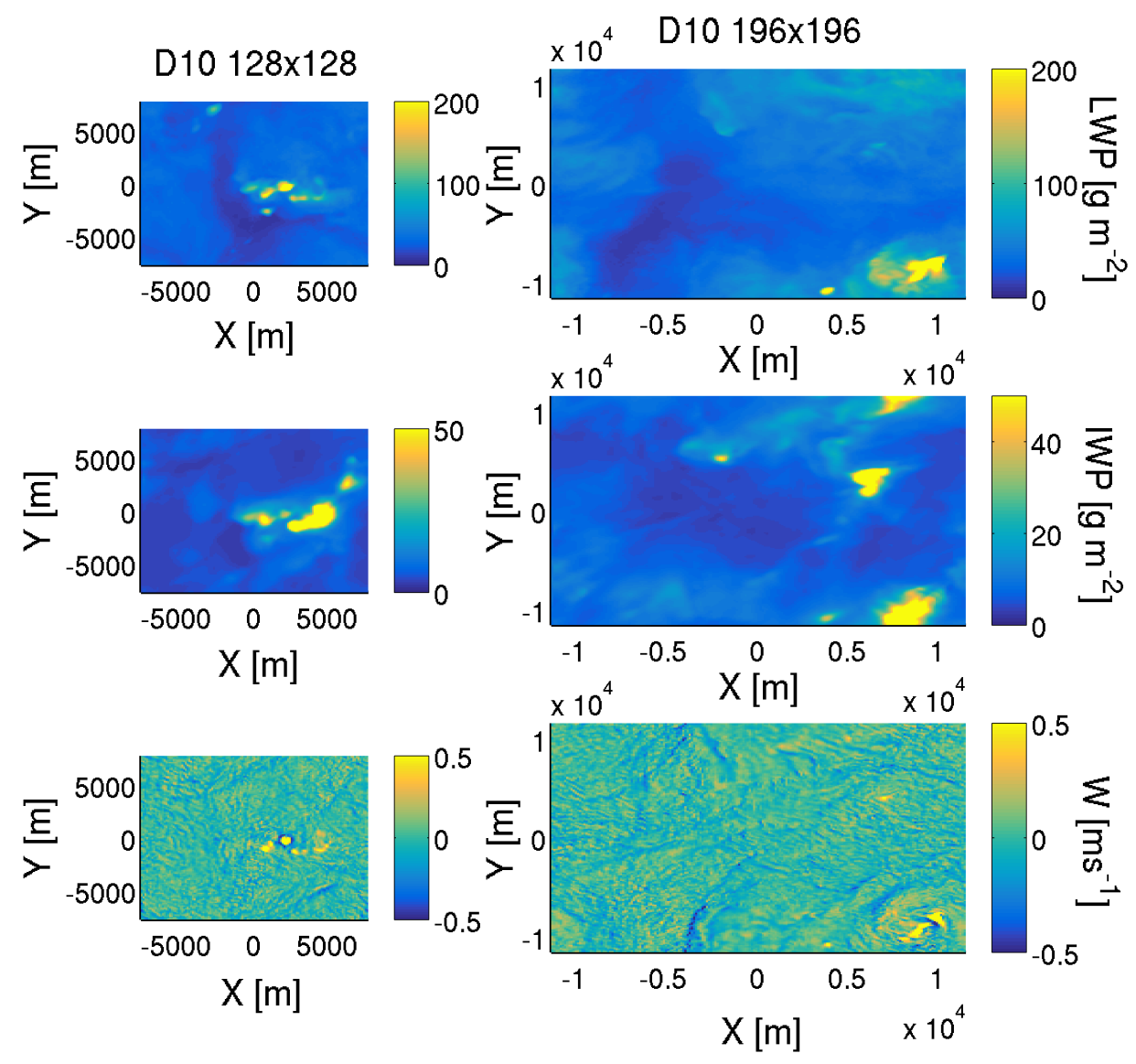

Figure S18. Modelled LWP (top row), IWP (second row), and W (at approximately $1500 \mathrm{~m}$, bottom row) for domain sizes $128 \times 128$ grid points (left column) and $196 \times 196$ grid points (right column) at $21 \mathrm{~h}$ into the simulations. Both domains use X/Y resolution of $120 \mathrm{~m}$ and use the same vertical domain size and resolution; the only difference is the domain size in X/Y. Convective cells - as shown by the hot-spots in LWP, IWP, and W - form in both cases, suggesting that these phenomena were not a result of the original domain specifications. Note changing colour bars for each subfigure. 

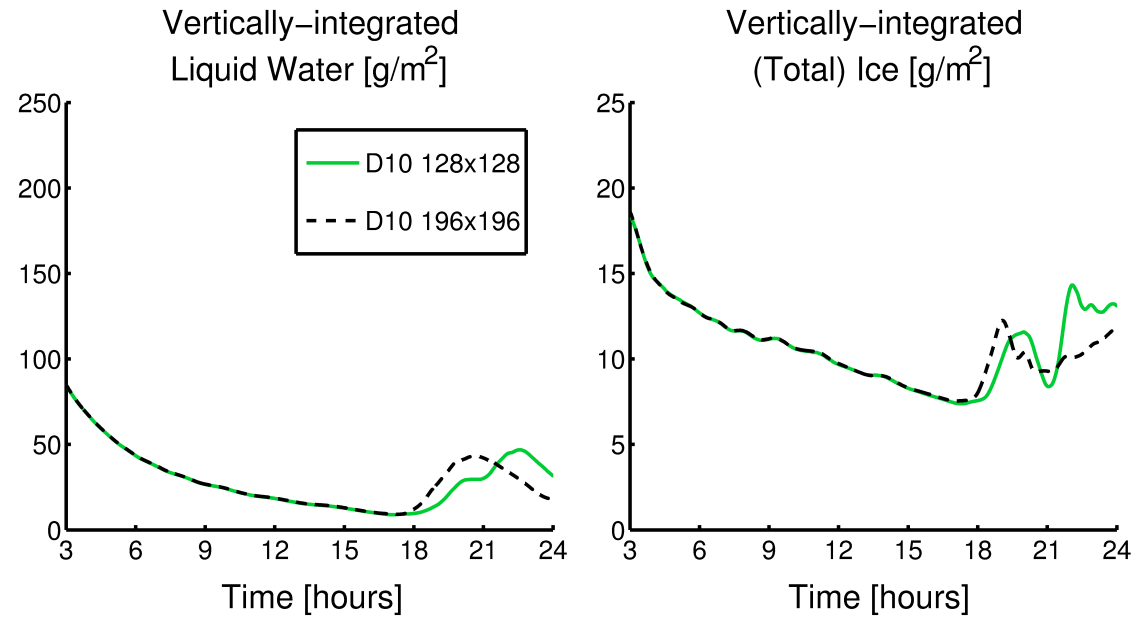

Figure S19. Modelled LWP (left panel) and IWP (right panel) with time for the original domain size $(128 \times 128$ grid points, green) and the larger domain size $(196 \times 196$ grid points, black) over the ocean (case 3). These traces diverge at approximately $18 \mathrm{~h}$; however, similar trends are seen. The feedbacks associated with convection and precipitation formation affect the evolution of the cloud properties, leading to different LWP and IWPs. These differences are due to the influence of the domain size on, for example, cloud radiative cooling and entrainment, leading to the formation of different convective cells, of different sizes, to the original domain.
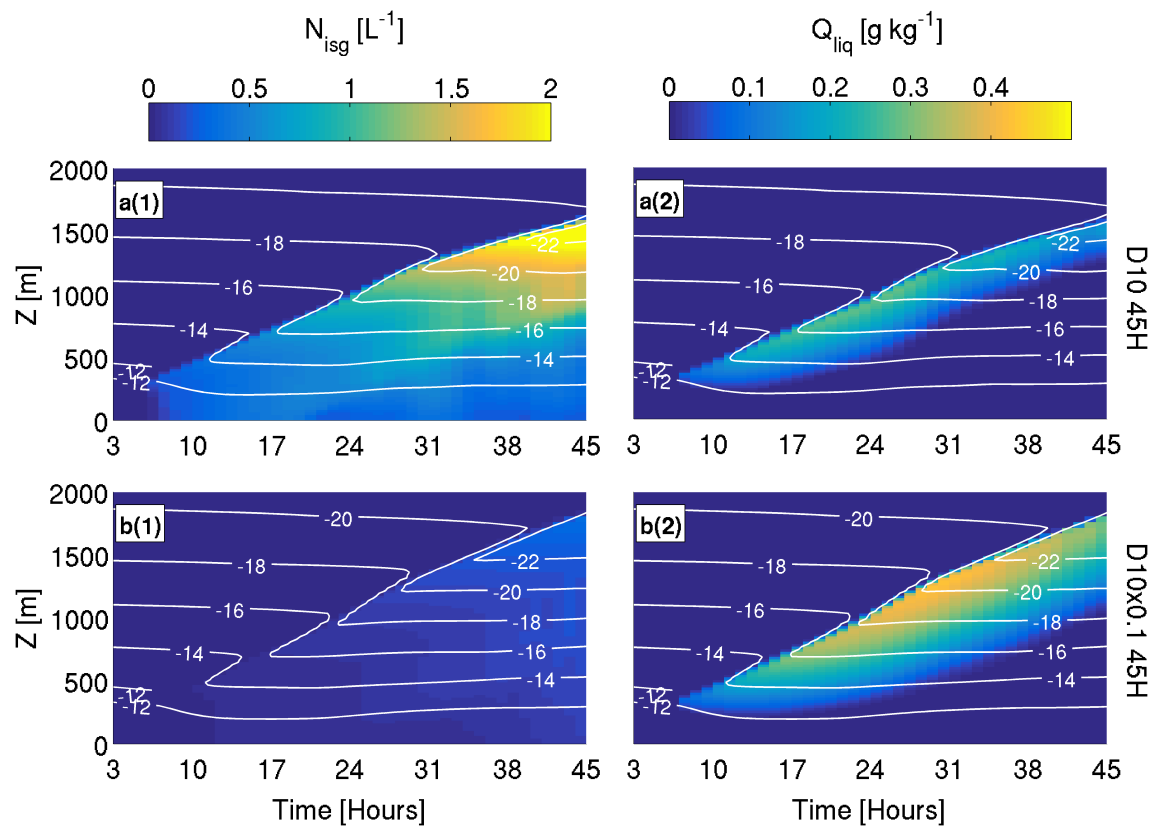

Figure S20. Modelled $\mathrm{N}_{\mathrm{isg}}$ (1) and $\mathrm{Q}_{\text {liq }}(\mathbf{2})$ when using (a) D10 and (b) D10 $\times 0.1$ to simulate case 2 over an extended run time of $45 \mathrm{~h}$. Note changing colour bars for each subfigure. 


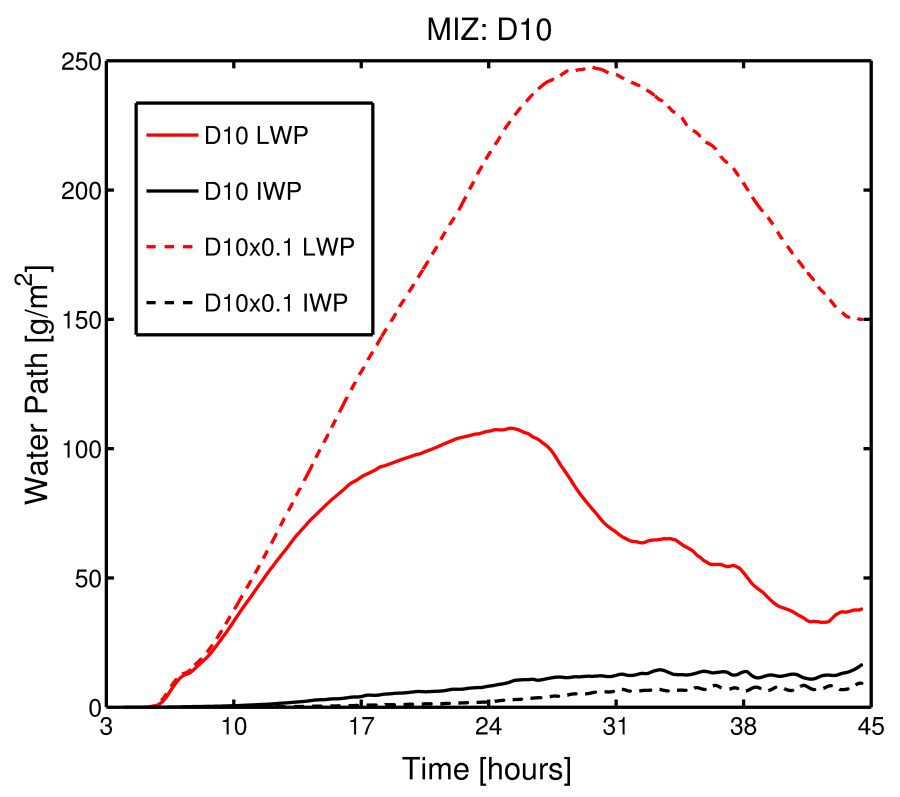

Figure S21. Modelled LWP (red) and IWP (black) when using D10 (solid) and D10 $\times 0.1$ (dashed) to simulate case 2 over an extended run time of $45 \mathrm{~h}$. 

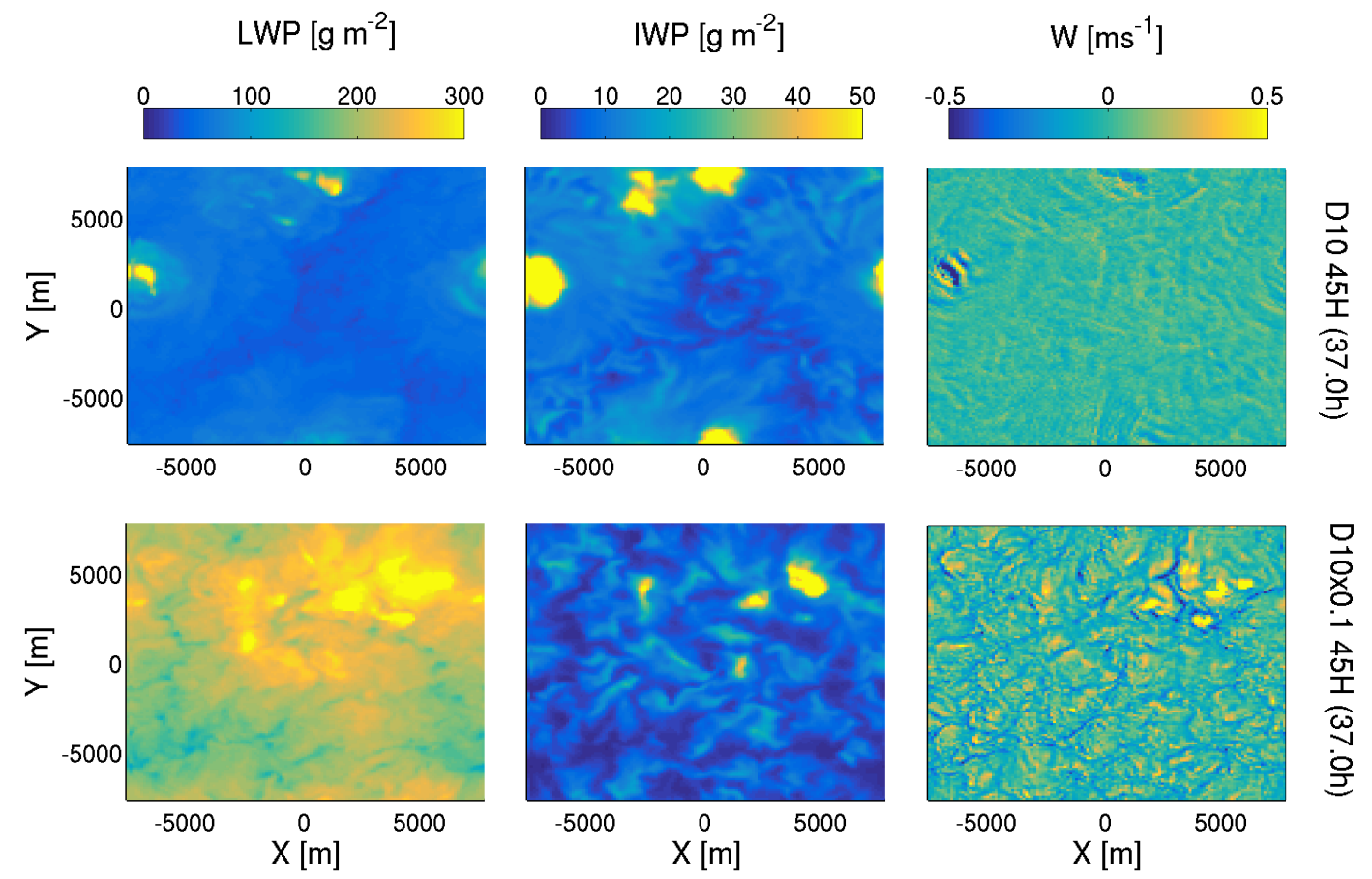

Figure S22. Modelled LWP (first column), IWP (second column), and vertical velocity (third column) at approximately $1500 \mathrm{~m}$ using D10 (top row) and $\mathrm{D} 10 \times 0.1$ (bottom row) to simulate case 2 . Planar X-Y slices are shown at $37 \mathrm{~h}$. Note changing colour bars for each subfigure. 

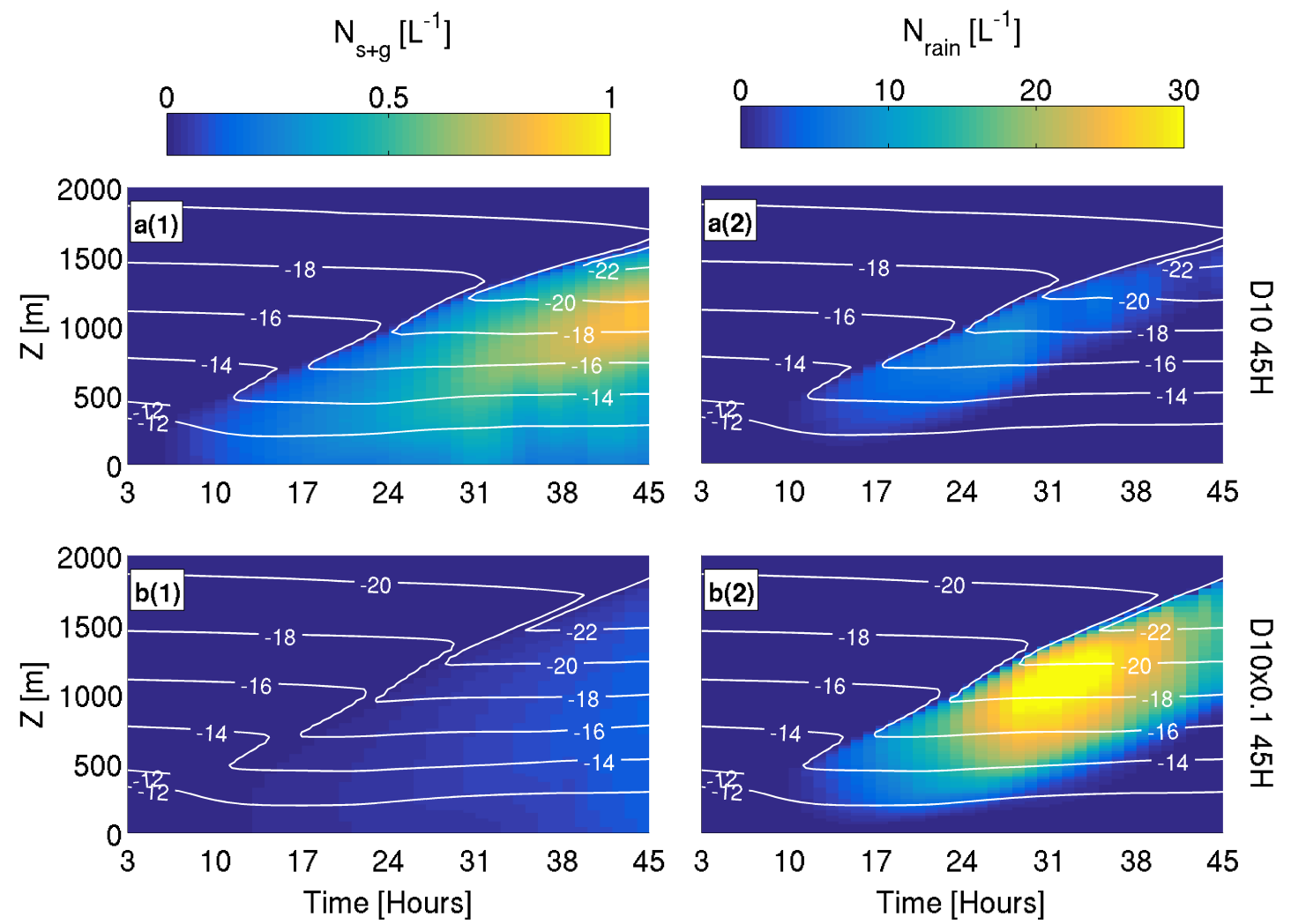

Figure S23. Modelled number concentrations of solid $\left(\mathrm{N}_{\mathrm{s}+\mathrm{g}}, \mathbf{1}\right)$ and liquid $\left(\mathrm{N}_{\mathrm{rain}}, \mathbf{2}\right)$ precipitable particles when using (a) D10 and (b) D $10 \times 0.1$ (bottom row) to simulate case 2 over an extended run time of $45 \mathrm{~h}$. Note changing colour bars for each subfigure. 